\title{
Tracking healing process of experimental liver injuries treated with different sealants and adhesives
} biomaterials. Matrix metalloproteinase evaluation.

José M. Lloris-Carsí, MD PhD; Carlos Barrios, MD PhD²; José M. Lloris-Cejalvo, UGS³; Luis Gil-Santos MD $\mathrm{PhD}^{2}$, Dolores Cejalvo-Lapeña, $\mathrm{PhD}^{3}$

1. Department of Surgery, University of Valencia, Spain

2. Valencia Catholic University, Institute for Research on Musculoskeletal Disorders

3. Division of Experimental Surgery, Valencia Catholic University, Spain

email and mailing address of all authors:

Lloris-Carsí, JM jm_lloris@mac.com

Department of Surgery, University of Valencia: School of Medicine, Av. Blasco Ibañez 15, 46010 Valencia, Spain,

Barrios, C carlos.barrios@ucv.es

Valencia Catholic University, Institute for Research on Musculoskeletal Disorders

Lloris-Cejalvo, JM josemiguel.lloris@mail.ucv.es

Gil-Santos, L Igil@hilevante.com

Cejalvo-Lapeña, D dolores.cejalvo@ucv.es

Division of Experimental Surgery, Valencia Catholic University, Quevedo 2, 46001 Valencia, Spain

Financial support: No funding was receive for this work

Author for Correspondence:

Dr. José Miguel Lloris-Carsí,

Department of Surgery, University of Valencia School of Medicine, Av. Blasco Ibañez 15,

46010 Valencia, Spain,

Tel: +34 670070 269;

Fax: +34 963864805 ;

Email: jm_lloris@mac.com

Abstract: Background. Sealants and adhesives are used in the repair and preservation of damaged solid organs. This study examines the matrix metalloproteinases (MMP) activity in the healing of liver injuries treated with two biological adhesives (Tachosil ${ }^{\circledR}$ and GelitaSpon ${ }^{\circledR}$ ) as well as that of a new elastic cyanoacrylate (Adhflex ${ }^{\circledR}$ ). Methods. We induced in 90 male rats hepatic lesions using a Stiefel biopsy punch in the liver. Wound healing was assessed 2, 6, and 18 days after injury by quantifying MMP1, 2, 8, 9, and 13 tissue levels. The histopathological repair was evaluated by hematoxylin-eosin, Masson's trichrome, and Periodic Acid Schiff (PAS) staining and CD31, CD68 immunohistochemical marker. The three sealants used contributed to the complete healing of hepatic lesions. Both histopathology and MMP findings point to the fact that degradation with Adhflex ${ }^{\circledast}$ is slower and causes a strong inflammatory reaction at the onset of healing. Results. All the MMPs measured showed higher values early in the healing process in animals treated with Adhflex ${ }^{\circledR}$ and Tachosil, expression for MMP2 and MMP9 being significantly higher in the Adhflex-treated group. Animals treated with Tachosil had significant greater values of MMP8 and MPP13 than the Adhflex group. Animals treated with Adhflex ${ }^{\circledR}$ showed a sustained overexpression in all MMPs even at the latest wound healing stages. Conclusion. Notably, the overexpression of the MMPs did not negatively influence the histological healing process of liver injuries. Since all hepatic trauma injuries should be treated as emergencies, any easy-to-use and rapid sealant, like Adhflex ${ }^{\circledR}$, could be considered an adequate treatment option.

Keywords: Hepatic injury, sealants, metalloproteinases, inflammatory response, wound healing. 


\section{Introduction}

Interest in the use of biological adhesives has increased since Dermabond, a cyanoacrylate specially designed for clinical use, was ratified by the Food and Drug Administration (FDA) in 1998. A variety of biological sealants and adhesives have been applied to control bleeding in cases of hepatic injuries $[1,2,3]$ and different endoscopic biopsies of solid organs. [4,5]

The liver is remarkably able to self-repair and regenerate following an injury [6]. Liver lesion and regeneration have both been related to complex extracellular matrix (ECM)-related pathways. While normal degradation of ECM substances like collagen or fibrin is an important feature of tissue repair and remodeling, irregular ECM turnover contributes to a variety of liver diseases [7]. Matrix metalloproteinases (MMPs) are the primary enzymes involved in ECM degradation during wound healing; they also favor cell migration, buildup of new components in the ECM, and the development and remodeling of regenerative tissue. [8]

Matrix metalloproteinases not only remodel the ECM, but they also regulate different immune responses. In addition, MMPs also play significant roles in diverse pathological processes such as cancer, multiple sclerosis and some skin disorders. [8] The activity of the matrix metalloproteinase is regulated on the basis of a combination of production control (for example, by Interleukin-1 and TNF- $\alpha$ ), the presence or absence of factors involved in transforming the proenzymes into their active forms and the direct action of MMP inhibitors (TIMPs). [9-11]

The clinical usefulness of measuring MMPs continues to expand thanks to advances in new, more-objective detection methods. [12] The assessment of MMPs, which is currently facilitating deeper molecular knowledge of the mechanisms of wound healing, therefore warrants the improvement of new therapeutic approaches. A recent investigation found that elevated MMPs in wound fluids from patients with acute traumatic injuries predicted both impaired healing and dehiscence of surgically closed wounds. [13] Some of the MMP-attributed roles in acute and chronic liver injury have been described, emphasizing the need for further experimentation to better understand their functions both in physiological conditions and during hepatic disease progression. [14]

As a result of technological developments, the use of tissue adhesives and glues for tissue approximation and hemostasis has increased in surgery. [1] Fibrin sealants are commonly utilized in liver surgery, but their effectiveness in routine clinical practice is not controversy-free. Tisseel/Tissucol and Tachosil provided the strongest adhesion to liver cross-sections in a canine model of hepatectomy. [2] These results may facilitate the optimum choice of fibrin sealants for this clinical procedure. [1] Additionally, a multi-center, randomized clinical trial evaluated the effectiveness and safety of a fibrin sealant patch in parenchymal bleeding. [2] This clinical trial confirmed that the fibrin sealant was safe and highly effective at controlling parenchymal bleeding following hepatectomy, regardless of the type of resection. [2]

This study focused on investigating the activity of MMPs during the healing of liver injuries treated with biological adhesives (Tachosil $^{\circledR}$, GelitaSpon $^{\circledR}$ and Adhflex $^{\circledR}$ (elastic cyanoacrylate). Histopathological alterations also were controlled during hepatic injury healing and related to MMP activity. The clinical usefulness of measuring MMP expression during the healing of penetrating liver injuries may provide new insights into the repair processes of these lesions and shed light on how liver tissues react to these biological and synthetic adhesives. The superior adhesiveness and clotting speed of Adhflex ${ }^{\circledR}$ compared with conventional treatments in other organs suggests that Adhflex ${ }^{\circledast}$ could be considered a useful sealant substance. $[14,15]$ 


\section{Results}

2.1. Matrix metalloproteinase expression: Of the MMPs included in the Mosaic ELISA MMP Panel, only MMP1, MMP2, MMP8, MMP9 and MMP13 were sufficiently expressed to be quantifiable (Fig 1) (Table 1).

\begin{tabular}{|c|c|c|c|c|c|c|}
\hline $\begin{array}{l}\text { Liver } \\
\text { MMPs }\end{array}$ & Time & $\begin{array}{l}\text { Untreated } \\
\qquad(n=4)\end{array}$ & $\begin{array}{l}A d h f^{\circledast} \\
(n=4)\end{array}$ & $\begin{array}{l}\text { GelSp }^{\circledR} \\
(n=4)\end{array}$ & $\begin{array}{c}\text { Tachs }^{\circledast} \\
(n=4)\end{array}$ & $\begin{array}{l}\text { Kruskal-Wallis test ( } p \\
\text { value) }\end{array}$ \\
\hline \multirow[t]{4}{*}{ MMP 1} & $T 1$ & $0,80 \pm 0,22$ & $2,75 \pm 0,39 *$ & $0,35 \pm 0,10^{*} \mp$ & $2,71 \pm 0,31 *+$ & 0.005 \\
\hline & $T 2$ & $0,85 \pm 0,09$ & $0,73 \pm 0,06$ & $1,02 \pm 0,10$ & $1,45 \pm 0,08^{*} \neq+$ & 0.005 \\
\hline & T3 & $1,02 \pm 0,16$ & $3,05 \pm 0,36^{*}$ & $0,96 \pm 0,18 \neq$ & $1,20 \pm 0,15 \ddagger$ & 0.016 \\
\hline & $\begin{array}{l}\text { Kruskal-Wallis } \\
\text { test ( } p \text { value) }\end{array}$ & $0.234^{n s}$ & 0.021 & 0.024 & 0.008 & \\
\hline \multirow[t]{4}{*}{ MMP 2} & $T 1$ & $1,81 \pm 0,11$ & $3,29 \pm 0,04^{*}$ & $1,16 \pm 0,11^{*} \ddagger$ & $2,27 \pm 0,06^{*} \mp+$ & 0.003 \\
\hline & $T 2$ & $1,45 \pm 0,09$ & $3,00 \pm 0,14^{*}$ & $2,12 \pm 0,06^{*} \ddagger$ & $4,04 \pm 0,13^{*} \ddagger \dagger$ & 0.003 \\
\hline & T3 & $1,55 \pm 0,50$ & $2,72 \pm 0,08^{*}$ & $1,41 \pm 0,07 \ddagger$ & $1,33 \pm 0,08 \ddagger$ & 0.024 \\
\hline & $\begin{array}{l}\text { Kruskal-Wallis } \\
\text { test ( } p \text { value) }\end{array}$ & $0.124^{n s}$ & 0.007 & 0.007 & 0.007 & \\
\hline \multirow[t]{4}{*}{ MMP 8} & $T 1$ & $0,68 \pm 0,09$ & $1,13 \pm 0,25^{*}$ & $0,33 \pm 0,05^{*} \mp$ & $1,28 \pm 0,05^{*+}$ & 0.005 \\
\hline & $T 2$ & $0,91 \pm 0,07$ & $0,62 \pm 0,08^{*}$ & $0,59 \pm 0,15^{*}$ & $1,10 \pm 0,08 \pm t$ & 0.007 \\
\hline & T3 & $0,84 \pm 0,11$ & $1,44 \pm 0,05^{*}$ & $0,78 \pm 0,10 \ddagger$ & $1,10 \pm 0,10^{*} \ddagger+$ & 0.005 \\
\hline & $\begin{array}{l}\text { Kruskal-Wallis } \\
\text { test ( } p \text { value) }\end{array}$ & $0.076^{n s}$ & 0.015 & 0.012 & 0.037 & \\
\hline \multirow[t]{4}{*}{ MMP 9} & $T 1$ & $1,27 \pm 0.08$ & $1,51 \pm 0,16^{*}$ & $0,34 \pm 0,04 * \mp$ & $1,44 \pm 0,05^{*}+$ & 0.005 \\
\hline & $T 2$ & $0,91 \pm 0,13$ & $0,45 \pm 0,14^{*}$ & $0,55 \pm 0,09$ & $0,90 \pm 0,16 \neq t$ & 0.009 \\
\hline & T3 & $0,91 \pm 0,13$ & $1,56 \pm 0,14^{*}$ & $0,77 \pm 0,11 \neq$ & $0,87 \pm 0,13 \ddagger$ & 0.020 \\
\hline & $\begin{array}{c}\text { Kruskal-Wallis } \\
\text { test ( } p \text { value) }\end{array}$ & 0.025 & 0.024 & 0.010 & 0.024 & \\
\hline \multirow[t]{4}{*}{ MMP 13} & $T 1$ & $1,42 \pm 0,06$ & $1,63 \pm 0,16$ & $0,39 \pm 0,04^{*} \neq$ & $1,99 \pm 0,10^{*+}$ & 0.003 \\
\hline & $T 2$ & $0,95 \pm 0,17$ & $1,51 \pm 0,10^{*}$ & $0,90 \pm 0,09^{*} \ddagger$ & $1,21 \pm 0,10^{\dagger}$ & 0.008 \\
\hline & $T 3$ & $1,18 \pm 0,08$ & $3,33 \pm 0,19^{*}$ & $1,38 \pm 0,11 \ddagger$ & $1,82 \pm 0,12 * \neq+$ & 0.003 \\
\hline & $\begin{array}{l}\text { Kruskal-Wallis } \\
\text { test } p \text { value) }\end{array}$ & 0.011 & 0.019 & 0.007 & 0.011 & \\
\hline
\end{tabular}

TABLE 1. MMP1, MMP2, MMP8, MMP9 and MMP13 metalloproteinase mean values ( \pm standard deviation) (pg/mL) in the three healing times (T1: 2 days after injury; T2: 6 days after injury, and T3: 18 days after injury) and in each treatment group. Mann-Whitney $U$ test: $\left({ }^{*}\right) p<0.05$ compared with untreated animals; ( $\left.¥\right) p<0.05$ with compared with the Adhfex ${ }^{\circledast}$ group; (†) $p<0.05$ compared with the GelSp ${ }^{\circledR}$ group. The Kruskal-Wallis test revealed the statistical differences among the four groups during each healing time period. (ns): no significance.

2.2. MMP1: Both time since injury and treatment method influenced MMP1 expression in the three treated groups (Kruskal-Wallis test for time, $p<0.05$; for treatment, $p<0.05$ ) (Table 1). Along the healing process (T1, T2 and T3), the untreated group did not exhibit any statistically significant 
difference in the MMP1 measurements. (Table 1, Fig 1-D). The highest mean MMP1 expression level was recorded in the Adhflex ${ }^{\circledast}$ group. The lowest mean MMP1 concentration in the treated group was recorded in the GelSp ${ }^{\circledR}$ group (Table 1). The Adhflex-treated group had the highest MMP1 concentration at 2 and 8 days after injury, and the difference was statistically significant higher at 18 days (T3 as compared with the other treatments (Table 1).

A
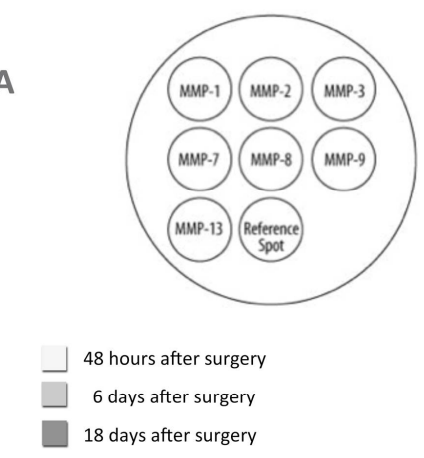

C

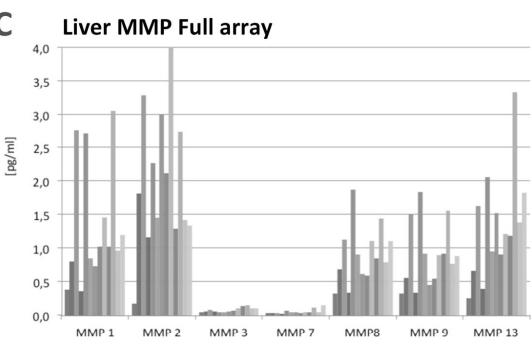

D
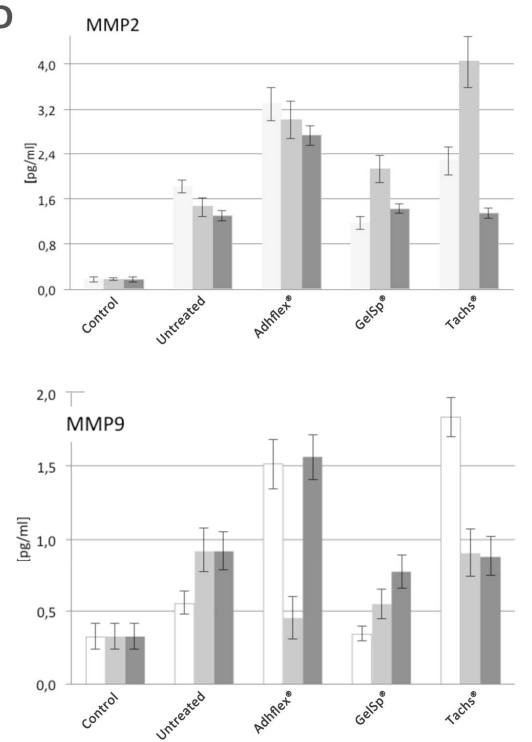

B
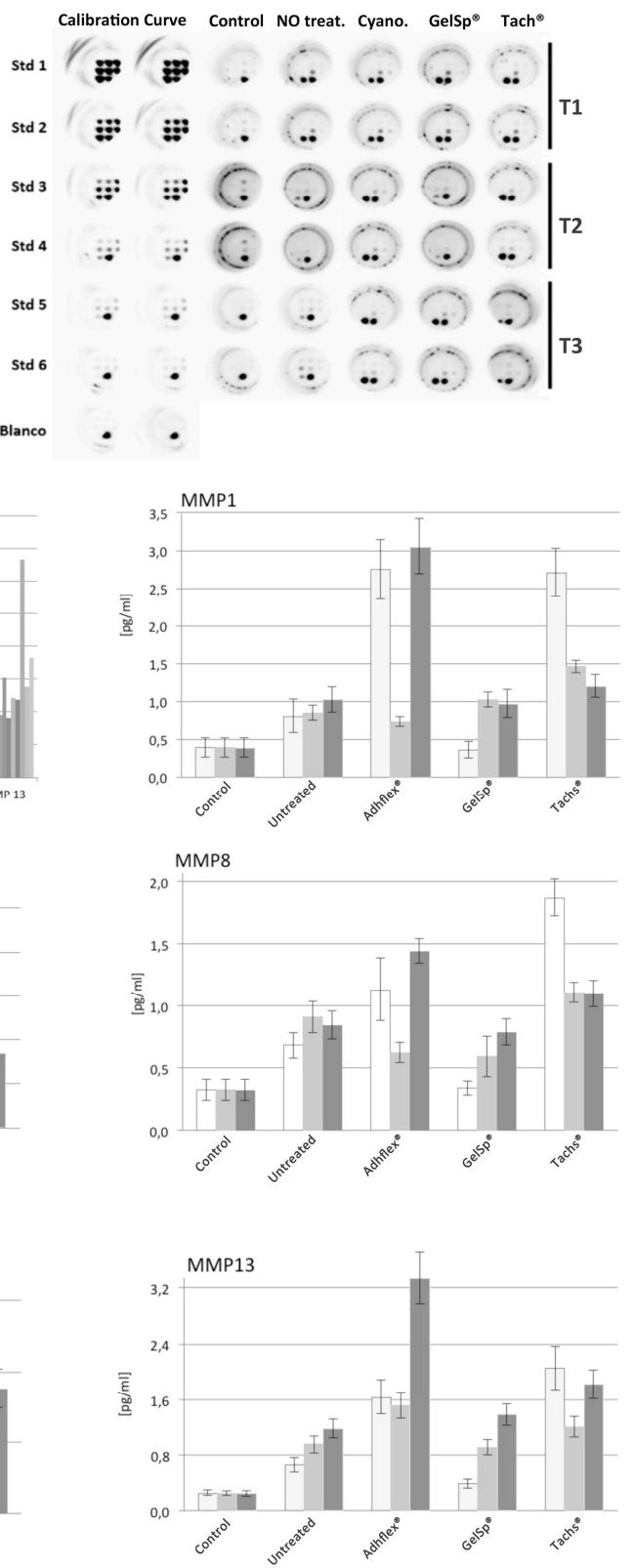

FIGURE 1. Metalloproteinase expression in sham-control, untreated and treated (Adhflex ${ }^{\circledR}$, and TachoSil) livers. (A) Chart showing the most expressive metalloproteinase; (B) ELISA MMP panel (R\&D Systems) plates of the rat metalloproteinase in all groups; (C) Individual graphs for the most expressed metalloproteinases in all groups (control, untreated, and Adhflex, GelitaSpon and TachoSil treated) tested at 2, 6 and 18 days after surgery and injuries. Mann-Whitney $U$ test: $\left({ }^{*}\right), p<0.05$ as compared to untreated animals; $(\neq), p<0.05$ as compared to Adhf ${ }^{\oplus}$ group; $(+), p<0.05$ as compared to Gelsp ${ }^{\circledR}$ group. Kruskal-Wallis test shows the statistical differences among four groups in each healing time period. $\left.{ }^{(n s}\right)$ : no significance.

2.3. MMP2: Except for the untreated group, significant differences were found in MMP2 expression between the 2, 6 and 18 days post-injury sampling times (Kruskal-Wallis test, $p<0.01$ ) (Table 1). 
MMP2 expression was also the highest 6 days post-injury and the lowest 18 days post-injury (Table 1) (Fig 1). The Tachosil-treated group had the highest concentration of MMP2 6 days after injury, and the difference was statistically higher that the concentrations exhibited by the other treatments (Table 1). Except for the Adhflex-treated animals, 18 days after injury all of the other groups restored normal expression of MMP2 compared with the control group.

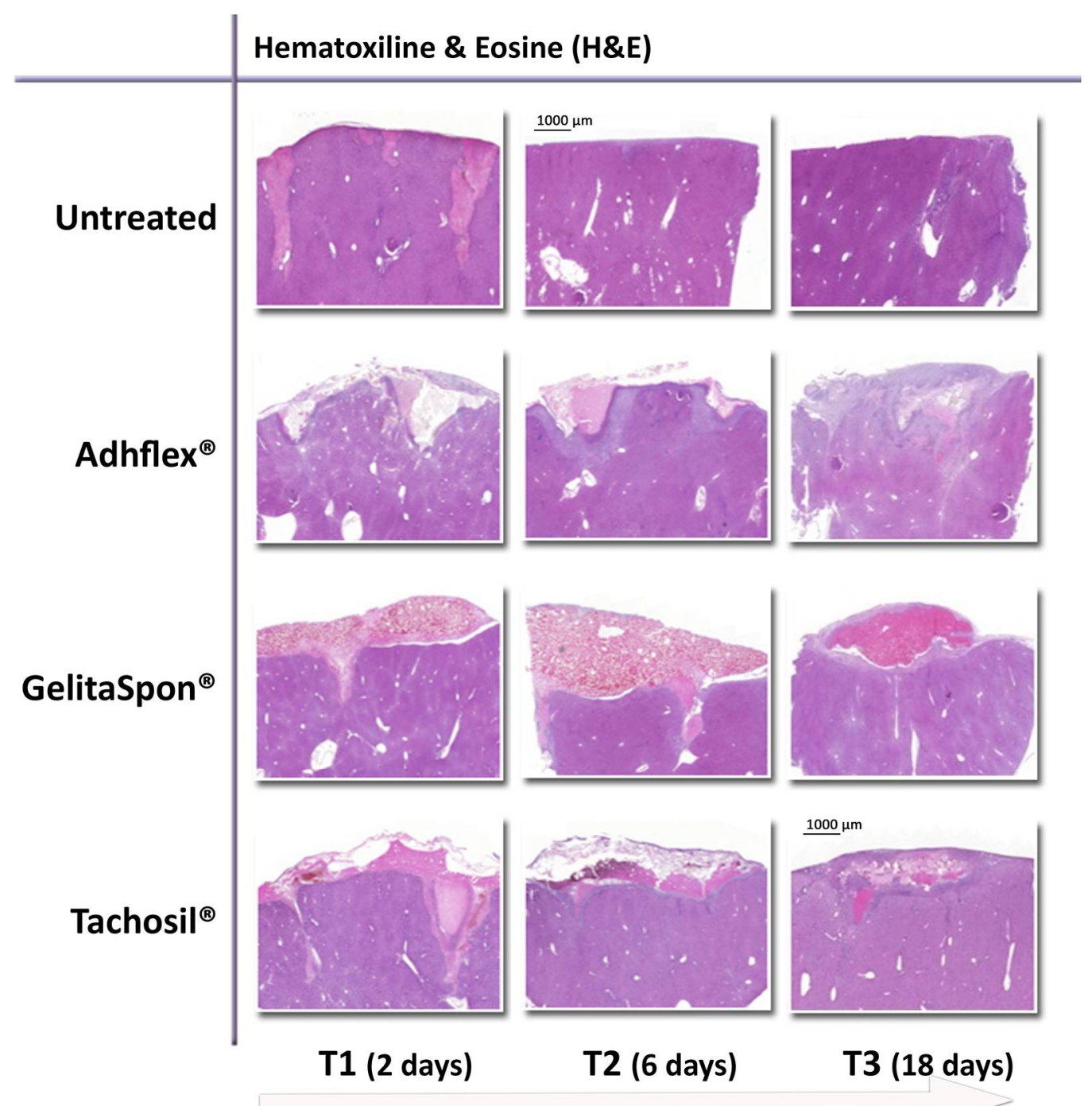

FIGURE 2. Hematoxiline \& Eosine stein (H\&E) Panel presenting the evolution of untreated and treated injuries (Adhflex, GelitaSpon, and Tachosil) in the liver groups.

2.4. MMP8: Like MMP1, both time since injury and treatment method influenced MMP8 expression. Significant differences in MMP8 expression between 2, 6 and 18 days post-injury were detected in the three treated groups $(p<0.05)$ but not in the untreated group (Table 1) (Fig 1-D). MMP8 concentration was lowest in the GelitaSpon (T1) group and significantly higher in the Tachs ${ }^{\circledR}$-treated group (Table 1) (Fig 1).

2.5. MMP9: MMP9 exhibited an expression pattern nearly identical to that of MMP8. Time since injury influenced MMP9 expression in all treated groups but that was not the case with untreated animals (Table 1). At T3, no differences were found between treated and untreated groups. The expression of 
MMP9 was lower in the GelitaSpon-treated group than in the untreated group. Like in the other MMPs, MMP9 expression was highest in the Adhflex-treated group, and the difference was statistically significant compared with the other treatments (Table 1) (Fig 1).

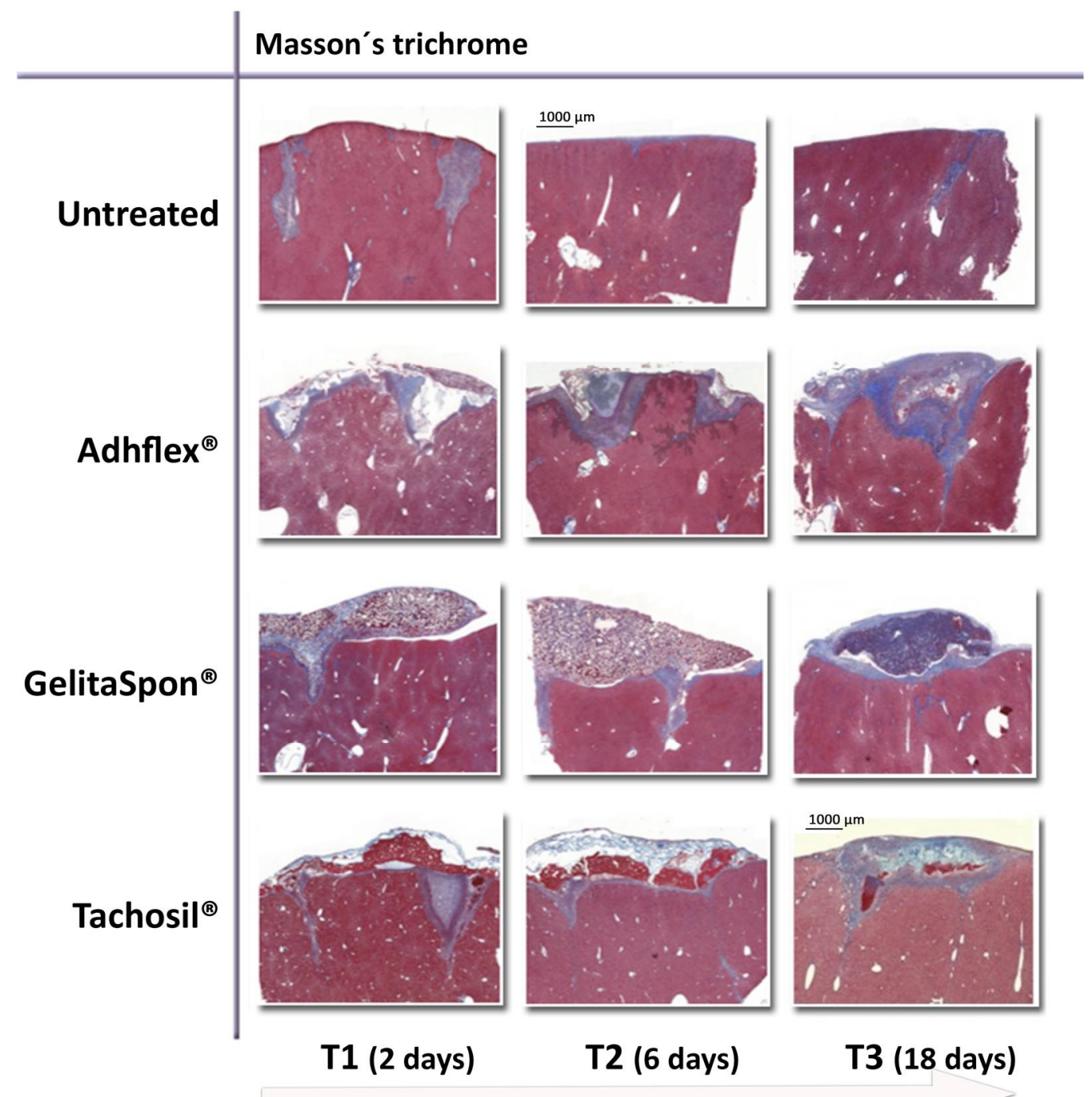

FIGURE 3. Masson's trichrome staining was used to visualize collagen and reticular fibers. Adhflex ${ }^{\circledR}$ generates an inflammatory reaction around the adhesive included in the wound (deep blue mark at the bottom of the lesions (T2 and T3).

2.6. MMP13: The expression of MMP13 followed a pattern similar to that of MMP8 and MMP9. Time since injury influenced MMP9 expression in all of the treated groups but not in the untreated animals (Table 1). There were significant differences in MMP13 expression between the untreated group and all three treated groups. The Adhflex-treated group exhibited the strongest MMP13 expression, which was significantly stronger than that of the other groups, particularly at the T3 stage (Table 1) (Fig 1).

2.7. Histological study. Figures 2-6 show tissue sections stained with hematoxylin and eosin, Masson's trichrome, Periodic Acid Schiff PAS, CD31 and CD68 immunohistochemical marker. Each staining made it possible to observe a different feature of the healing lesions. For all of the tests in the untreated liver lesions (two days - T1), the wounds produced by the Stiefel biopsy punch were well defined, and a dark strip compatible with granulation tissue, comprising inflammatory cells and fibroblasts, was observed. 
The necrotic tissue had completely disappeared 18 days post-injury, and wound edges were fully in contact. A column of dark violet connective tissue could be observed corresponding to the injury scar. The appearance of the parenchyma surrounding the scar was normal.

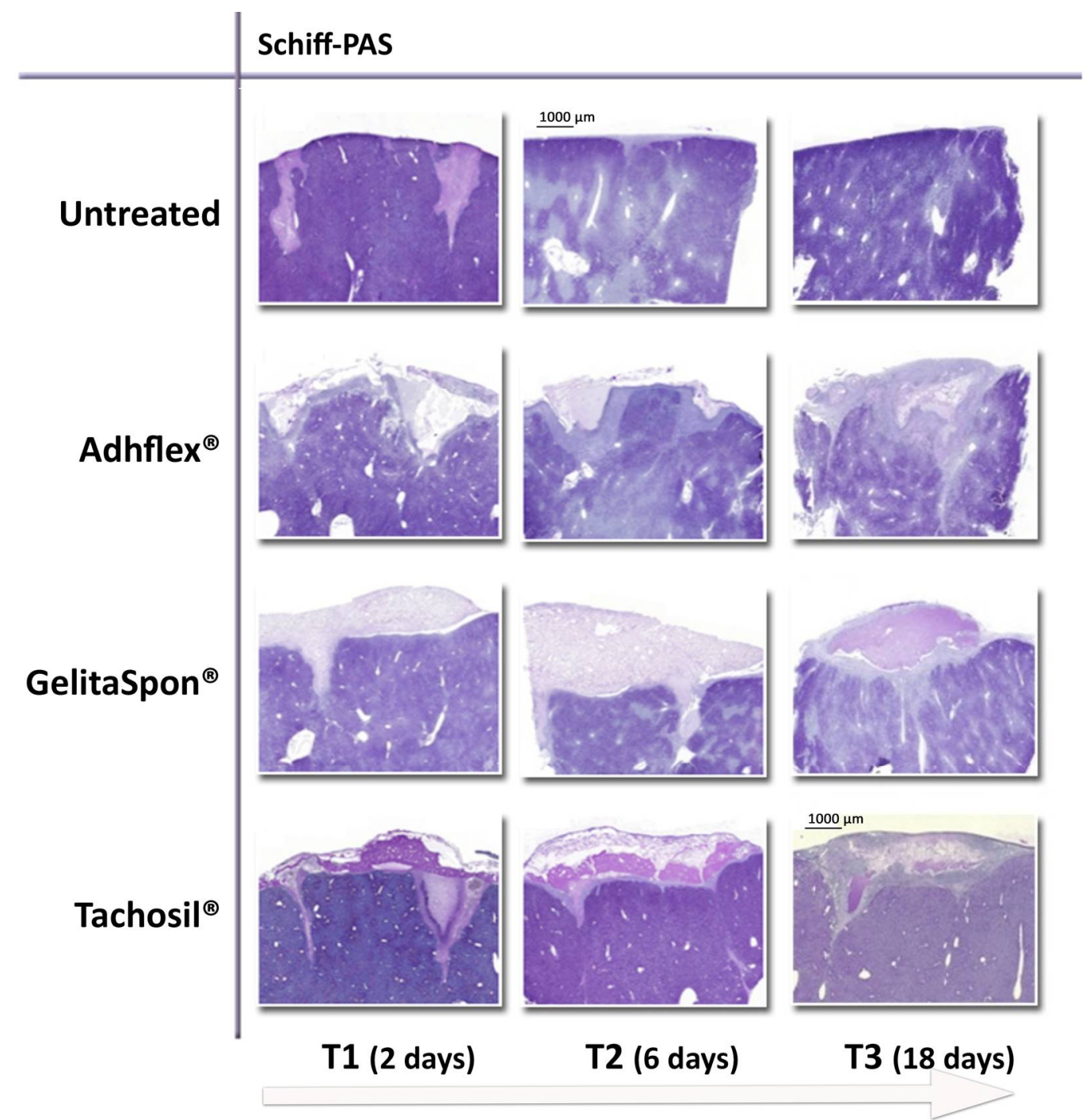

FIGURE 4. Periodic Acid Schiff (PAS) staining was used to identify glycogen and mucin. The color contrast of the stains reveals each part of the lesions very well and the biomaterials used for wound sealing.

By studying all of the stains, the evolution of lesions and the behavior of the sealants that we used could be clearly assessed. In the untreated group at 18 days (T3), lesions were fully healed. In contrast, the wounds that were treated exhibited traces of the biomaterial adhered at the bottom of the lesions at 18 days. Additional comments are included in figure captions (Figs 2-6). 


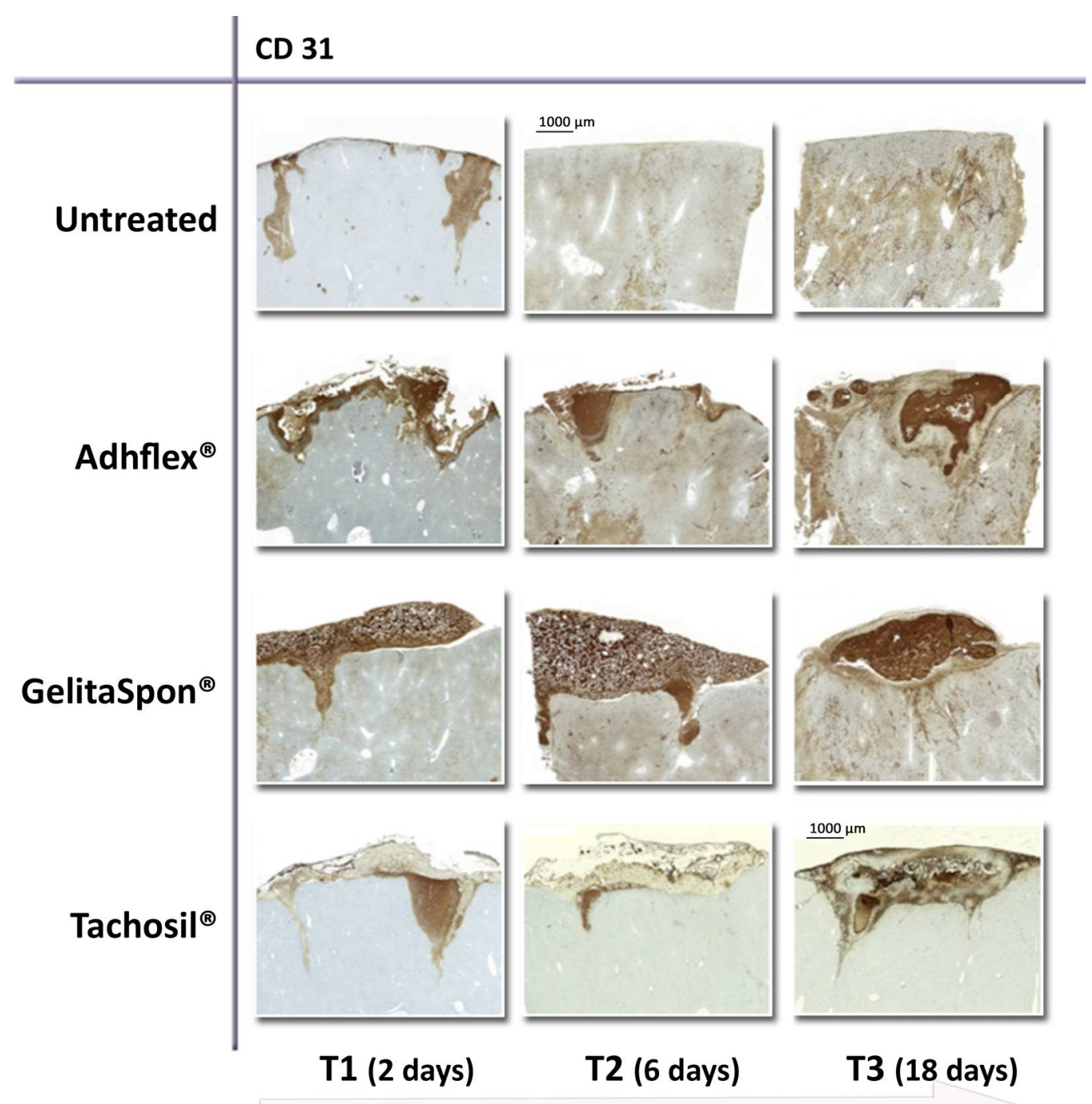

FIGURE 5. CD31 immunohistochemical marker is selective for endothelial cells associated with vascular neoformation. This marked wound shows the injuries produced by the punch in the untreated group at 2 days staining (T2). The contact of the materials used to treat the lesion is very well defined in this staining.

\section{Materials and Methods}

3.1. Ethical aspects: The animal welfare procedures and experimental design were approved by the Committee of Animal Welfare (Ethics Committee for Animals Studies) of the Regional Government of Valencia (reference number: VSC/2015/PEA/00097), pursuant to the legislation in force (ref.53/2013 Royal Decree) and FDA recommendations related to welfare of experimental animals.

3.2. Study design : Using an experimental rat model, hepatic injuries were made on the anterior aspect using a Stiefel Biopsy Punch (8 $\mathrm{mm}$ diameter, $3 \mathrm{~mm}$ depth), followed by local treatment with either TachoSil $^{\circledast}$, GelitaSpon ${ }^{\circledR}$ or Adhflex ${ }^{\circledR}$. An untreated injured group was also included. Wound healing was evaluated 2,6 and 18 days post-injury. 


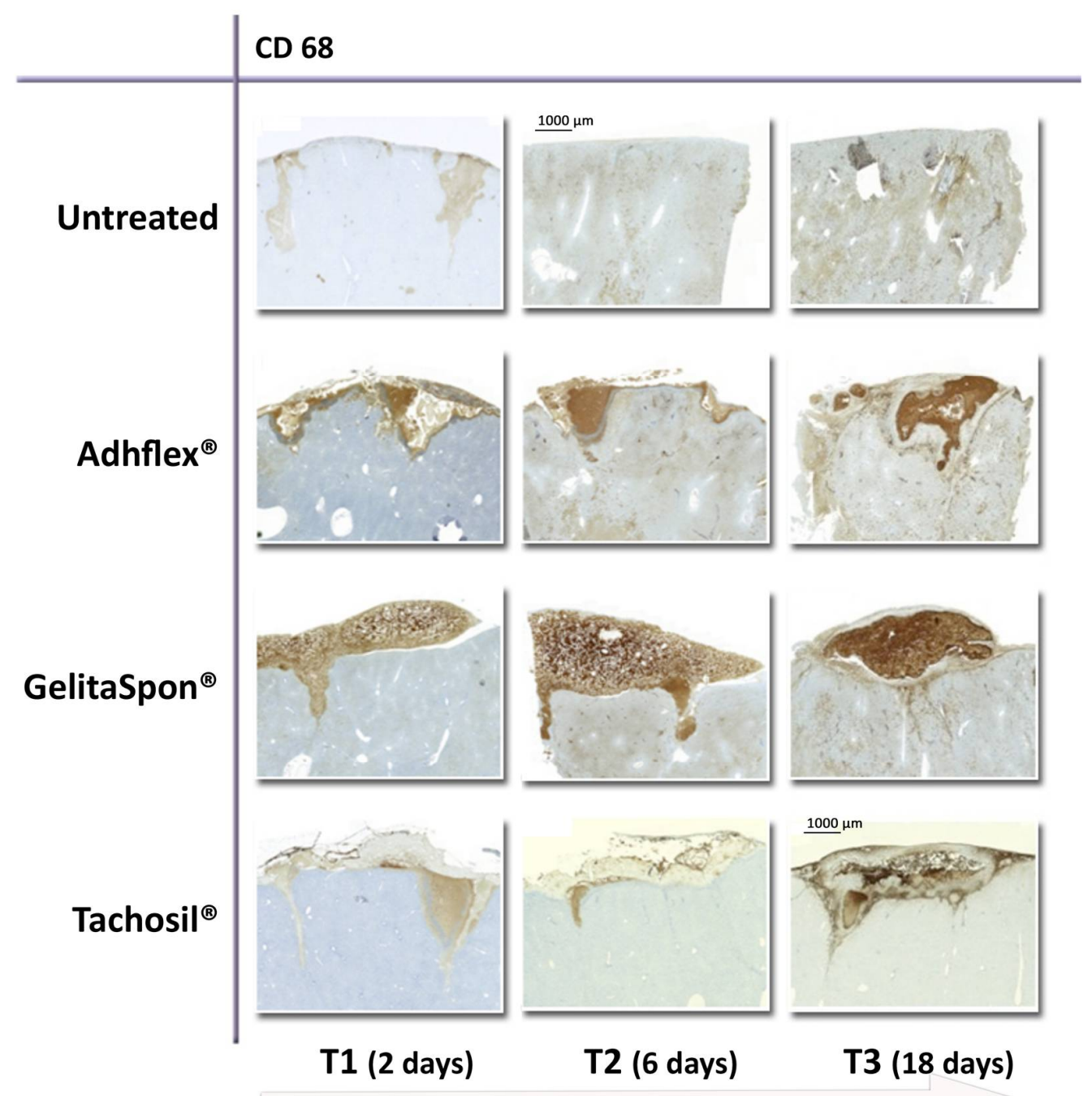

FIGURE 6. CD68 marker detects the cytoplasm of mast cells and histiocytes, which are the macrophages present in the post-trauma inflammatory process. As is the case with the CD31 immunohistochemical marker, panel images show very well the contact of the sealants employed and the evolution of wound healing.

3.3. Laboratory animals: 90 Wistar rats (body weight: $300-350 \mathrm{~g} / \mathrm{male}$ ) (Harlan Laboratories, Barcelona, Spain) were housed in a standard animal facility, with both pre-operative and post-operative access to food and water. Animal care and surveillance was conducted every 12 hours during the preoperative time and especially all 6 hours in the postoperative period, during 18 days. There were no deaths or illness during the whole period of the experiment

3.4. Groups studied: The rats were divided into: 1 : sham non-injured $(n=3) ; 2$ : untreated group $(n=6) ; 3$ : TachoSil-treated group ( $n=27) ; 4$ : GelitaSpon-treated ( $n=27)$, and 5: Adhflex-treated group $(n=27)$. For each group of animals, 4 rats were used for MMP expression and 5 rats were used for histological studies in a follow-up of 3 periods of the study: 2,6 and 18 days post-injury ( $9 \times 3=27$ rats). Untreated rats ( 2 animals) were used to study both histology and MMP expression in each study phase $(2 \times 3=6)$.

3.5. Biomaterials and adhesives used: To seal wounds generated by the punch, we use various sealants and adhesives: TachoSil ${ }^{\circledR}$ : haemostatic sponge with human fibrinogen $\left(5.5 \mathrm{mg} \mathrm{per} \mathrm{cm}^{2}\right)$ and thrombin $(2.0$ IU per $\mathrm{cm}^{2}$ )(Takeda GmbH-Austria) ${ }^{\circledR}$. GelitaSpon ${ }^{\circledR}$ : absorbable, oxidized cellulose sponge (Gelita Medical 
GmbH-Germany). Adhflex ${ }^{\circledR}$ : a cyanoacrylate-based adhesive supplemented with acrylates to boost elasticity, reduce stiffness, and enhance cohesive strength (Bioadhesives Medtech Solutions-Spain). Adhflex ${ }^{\circledR}$ has a lower polymerization temperature than other cyanoacrylates used in clinical practice and a marked elasticity. All three products possess adhesive and coagulant properties

3.6. Anaesthesia: All animals were anesthetized intraperitoneally (Ketamine $-80 \mathrm{mg} \mathrm{kg}^{-1}$ ) \& (Xylazine -10 $\mathrm{mg} \mathrm{kg}{ }^{-1}$ ) which kept a spontaneous breathing, during a abdominal laparotomy. To control an optimal hematosis, partial $\mathrm{O}_{2}$ and $\mathrm{CO}_{2}$ pressures were monitored, throughout the surgery. For the pain treatment was used (Buprenorphine - $0.1 \mathrm{mg} / \mathrm{kg}$ every $12 \mathrm{~h}$ ) during the first 48 hours after the surgical procedure.

3.7. Standardized treatments: After the anaesthesia, a laparotomy was performed to expose the liver. With direct vision, we performed lesions in the anterior area of the liver with a Stiefel biopsy punch. The selected trocar performed the same lesions ( $8 \mathrm{~mm}$ diameter) and depth $(4 \mathrm{~mm}$ ) over the surface with a slight twist. In GelitaSpon ${ }^{\circledR}$ and TachoSil $^{\circledR}$ groups, wounds were covered with homogeneous circles of the biological adhesives. In Adhflex ${ }^{\circledR}$ group, a drop (21.3 $\pm 1.2 \mathrm{mg}$ ) was applied onto each lesion. To ensure hemorrhagic occlusion, the liver was observed for several additional 3 minutes after sealing the injury. Lastly the abdominal incision was sutured in two layers.

3.8. Euthanasia: On days 2, 6 and 18 post-injury, 9 animals from each group were euthanized by means of an intraperitoneal injection (Sodium pentobarbital - $60 \mathrm{mg} / \mathrm{kg}$ - lethal dose,). The samples were processed for MMP determination and histology.

\subsection{Mealing monitoring:}

3.9.1. Metalioproteinases evolution: During healing, the activation and inhibition of different MMPs have an influence on multiple processes. To test whether or not TachoSil ${ }^{\circledR}$, GelitaSpon $^{\circledR}$ or Adhflex $^{\circledR}$ favoured local secretion of MMPs by the host hepatic cells, liver homogenates (serum-60 $\mu$ ) were subjected to enzyme-linked immunosorbent assay (ELISA) with MMPs (Mosaic ELISA MMP Panel, R\&D Systems).

Matrix metalloproteinases were quantified via chemiluminescence (as per the manufacturer's instructions). MMP-1, MMP-2, MMP-8, MMP-9 and MMP-13 levels were quantified. Both the panel and the protocol have a sensitivity within the $\mathrm{pg} / \mathrm{ml}$ range. MMP levels were quantified by means of gel densitometry (Image J), using the mean of duplicate samples. Equal spot sizes were studied per blot. The Mosaic ELISA MMP Panel can detect up to 7 different MMPs. Yet, due to sensitivity limitations, our analyses were solely focused on the most strongly expressed MMPs.

3.9.2. Histological studies: Haematoxylin-Eosin staining ( $3 \mu \mathrm{m}$ thick slices) was utilized for the samples study. Specific stains were used in order to identify histological changes caused in the development of hepatic lesions and the effects of several treatments. Five liver tissue samples from each group were examined. Masson's trichrome staining protocol was used to visualize collagen and reticular fibers, highlighting the increased apposition of collagen at the time of healing.[16] Periodic Acid Schiff (PAS) staining was used to identify glycogen and mucin.[17] Five liver tissue samples from each group were examined. The CD31 immunohistochemical marker is selective for endothelial cells associated with vascular neoformation.[18] The CD68 marker detects a glycoprotein (approximately 110 kD) in the cytoplasm of mast cells and histiocytes, which are macrophages present in the post-trauma inflammatory process. [19]

3.10. Statistical analysis: SPSS Statistics (v. 20.0, IBM-NY, USA) was used in all of the statistical analyses. 
Fisher's Least Significant Difference (LSD) test was applied to identify significant inter-group differences $(p<0.05)$ in the size of the gap between wound edges. Given the small sample size of our rat cohort, we used the non-parametric Kruskal-Wallis test to compare differences in MMP expression across groups. The Mann-Whitney $U$ test was used to study differences in MMP expression between the untreated group and each treated group. $P$-values under 0.05 were considered to be statistically significant. Normality and Levene's test were used to assess the equality of error variance for each variable.

\section{Discussion}

This study describes changes in MMP expression after application of three surgical sealants (TachoSil, GelitaSpon, Adhflex) in an experimental penetrating hepatic injury. As has been described for renal injuries [14], the histological healing process of hepatic lesions in response to the three biomaterials was comparable. However, MMP expression varied depending on the sealant used. All of the MMPs exhibited higher expression at early stages of the healing process ( 2 days) in animals treated with Adhflex and Tachosil. Differences between these two sealants were statistically significant only for MMP2 and MMP9, and expression was higher in the Adhflex-treated group. In the case of MMP8 and MPP13, animals treated with Tachosil had significant higher values of these MMPs than the Adhflex-treated group. Apart from the overexpression of MMPs at early stages of wound healing, animals treated with Adflex displayed a maintained overexpression in all of the MMPs tested, even at the latest wound healing stages (18 days post-injury). Notably, this MMP overexpression did not negatively influence the histological healing process of hepatic injuries.

Matrix metalloproteinases are a family of proteases that use zinc-dependent catalysis to break down ECM glycoprotein, which allows cells to move and tissue to reorganize. [20] At the present time, there is strong evidence that MMPs play key roles in the healing process, especially during the inflammatory and proliferative phase. [10-13] Consequently, the sampling times used here were defined in line with the inflammatory, proliferative and maturation stages of injury healing.[21] Most MMPs operate simultaneously, at times even sharing substrates, with the activity of one MMP often causing others to become active. It is for that reason that comparisons were made here between groups of MMPs arranged into defined subfamilies. [22]

Even though MMP involvement in pathology is more than mere excessive matrix degeneration or an imbalance between MMPs and their specific TIMPs, MMP inhibition may be therapeutically beneficial: synthetic MMPs inhibitors have therefore been developed and are currently being tested at clinical level. [23] MMPs and their specific inhibitors (TIMPs) play a pivoting role in both fibrogenesis and fibrolysis in the liver. [24]

Of the MMPs tested, only collagenases (MMP1, MMP8 and MMP13) are able to break down the triple helix of fibrillar collagen. In our study, collagenases had differing expression profiles.

MMP1 expression was higher in the Adhflex- and Tachosil-treated groups than in the untreated group. The highest MMP1 expression was recorded for the Adhflex-treated group 18 days post-injury (Table 1 \& Fig 1-C). According to the histopathology findings, the high MMP1 values coincide with a persistence of biomaterial in the lesion (Figs 3-6). Therefore, the increased expression of MMP1 might be related to the persistent inflammatory reaction induced by Adhflex $^{\circledR}$ at that healing time. In fact, when an injury becomes chronic, as is the case with dermal ulcers caused by burns, MMP1 concentration remains high after the first week of healing. [25] Prolonged MMP1 activity in chronic skin ulcers can have a critical effect on tissue re-epithelialization.[26]

Gelatinases (MMP2 and MMP9) play an important role in the formation and maturation of granulation tissue during wound healing. [27] Both MMP2 and MMP9 have been reported to act synergistically with 
collagenases. [28] Once collagenases have cleaved the collagen triple helix, gelatinases begin degrading the Type I, II and III collagen fibers.

MMP2 has been found to delay fibroblast differentiation during healing [29]. Therefore, controlling MMP2 activity could be a way of preventing hypertrophic scarring. A number of authors have reported increased gelatinase expression following traumatic injury. [30,31] Nessler[28] measured MMP2 expression levels in patients with healing wounds ( 1,7 and 25 days post-injury) finding the highest levels 7 days after the injury, which is in line with other papers which typically found MMP expression to peak between day 5 and day 7 post-injury, this coinciding with completion of the inflammatory phase and formation of granulation tissue. [32] These data are in accordance with the current findings in which MMP2 was significantly higher in samples taken 6 days after injury, particularly in the Tachosil-treated animals.

While MMP2 expression is important during the remodeling phase, the gelatinolytic activity of MMP9 appears to be higher in early wound healing. This finding is in line with our findings of MMP9 peak values during the early wound healing stage in the control and the GelSp-treated groups. However, in the Adhflex ${ }^{\circledR}$ and Tachs ${ }^{\circledR}$ groups, MMP9 activity remained high 18 days after injury. The finding that MMP9 expression peaked between 2 and 6 days post-injury may be associated with the normal healing process. The histological findings indicate that $\mathrm{Adhflex}^{\circledR}$ and $\mathrm{Tachs}^{\circledR}$ treatments yield stronger inflammatory reactions on liver tissue throughout the healing process and possibly contribute to the increased expression of MMP9 (Figs 3-6 in the Adhflex ${ }^{\circledR}$ - and Tach $^{\circledR}$-treated samples),

The predominant role of MMP8 in ECM turnover, modulation of inflammatory responses and other physiological processes is well documented. [33] MMP8 is stored in the granules of neutrophils and is released in the first few hours following an injury. Its activity can last up to the end of the inflammatory phase. [33-35] In this study, MMP8 expression peaked 2 days post-injury in animals treated with Tachosil and 18 days post-injury in animals treated with Adhflex ${ }^{\circledast}$. In the GelSp-treated groups, MMP8 values were below the reference controls during the entire healing process. The MMP8 expression profiles described here are consistent with a normal healing process.

MMP13 expression was high at all stages of the healing process post-injury and was highest in the Adhflex-treated group 18 days after injury. MMP13 expression was initially higher in the Tachosil-treated group. The GelSp sealant did not induce any effect on MMP13 expression. Several studies have pointed out that MMP13 activity in the early stages of healing is beneficial and is associated to the formation of the three-dimensional collagen matrix, as well as to changes in fibroblast morphology and viability. [30,36] MMP13 also influences the activity of myofibroblasts and angiogenesis, particularly when granulation tissue is formed. [31] In spite of such positive effects, high MMP13 expression has also been reported in many chronic skin disorders, as well as in other chronic conditions such as rheumatoid osteoarthritis, where it results in the destruction of the collagen matrix. [36] The stronger expression of MMP13 in the Adhflex ${ }^{\circledR}$-treated samples after 18 days may be the consequence of the remaining cyanoacrylate at the bottom of the wounds (Figs 3-5).

As regards the histopathology analyses, healing progression was similar for all study groups. The application of each individual sealant caused a marked coagulated hematoma in the area affected. Over time, granulation tissue was noticeable around the necrotic area, with highly dispersed inflammatory infiltration. The scar tissue initially covered a relatively large surface area in the days following the lesion. However, after 18 days the size of the scar area was significantly reduced (Fig 3). Eighteen days post-injury, the necrotic tissue had been eliminated in almost all samples and had been replaced by a strip of 
connective tissue. This tissue formed a scar and showed signs of contraction that indicated maturation of the scarred tissue. Healing progress was similar regardless of the sealant used.

\section{Conclusions}

In conclusion, the three sealants used in this study yielded complete healing of the liver lesions. Both the histopathology and MMP findings indicate that the degradation process of Adhflex ${ }^{\circledR}$ was slower than the other biomaterials, and produced a strong initial inflammatory reaction. However, at the end of the process, we noted complete healing of the lesions. Given that all hepatic trauma injuries should be considered emergencies, any easy-to-use and rapid sealant such as Adhflex ${ }^{\circledR}$ could be considered to be a suitable treatment option.

Acknowledgments: The authors wish to thank the Institute of Pathology headed by Professor Jerónimo Forteza.

Author Contributions: Lloris JM: conceptualization, methodology, supervision, writing - original draft; Barrios C: data curation, investigation, methodology, validation, writing-review \& editing; Lloris-Cejalvo: methodology, proyect administration, resources; Lloris-Salvi: data curation, format analysis, validation; Cejalvo-Lapeña : conceptualization, data curation, investigation, writingreview\& editing

Conflicts of Interest: The authors alone are responsible for the content and writing of the paper. The authors declare no conflict of interest.

\section{REFERENCES}

1. Lacaze L, Le Dem N, Bubenheim M, Tsilividis B, Mezghani J, Schwartz L, Francois A, Ertaud JY, Bagot d'Arc M, Scotté M. Tensile strength of biological fibrin sealants: a comparative study. J Surg Res. 2012 Aug;176(2):455-9

2. Koea JB, Batiller J, Aguirre N, Shen J, Kocharian R, Bochicchio G, Garden OJ. A multicentre, prospective, randomized, controlled trial comparing EVARREST ${ }^{\mathrm{M}}$ fibrin sealant patch to standard of care in controlling bleeding following elective hepatectomy: anatomic versus non-anatomic resection. HPB (Oxford). 2016 Mar;18(3):221-8.

3. You KE, Koo MA, Lee DH, Kwon BJ, Lee MH, Hyon SH, Seomun Y, Kim JT, Park JC.The effective control of a bleeding injury using a medical adhesive containing batroxobin. Biomed Mater. 2014 Apr;9(2):025002.

4. Esposito C, Damiano R, Settimi A, De Marco M, Maglio P, Centonze A. Experience with the use of tissue adhesives in pediatric endoscopic surgery. Surg Endosc. 2004 Feb;18(2):290-2. Epub 2003 Dec 29.

5. Martin-Mateos RM, Lopez-San Roman A, García-Sánchez C, Garcia-Hoz F, Gil-Grande LA, Gómez EG, García-González M. Fibrin-glue-sealed liver biopsy: indications, complications and results. J Gastrointestin Liver Dis. 2014 Mar;23(1):100-1

6. Duarte S, Baber J, Fujii T1, Coito AJ.Matrix metalloproteinases in liver injury, repair and fibrosis. Matrix Biol. 2015 May-Jul;44-46:147-56.

7. Sheets AR, Massey CJ, Cronk SM, lafrati MD, Herman IM (2016) Matrix- and plasma-derived peptides promote tissue-specific injury responses and wound healing in diabetic swine. J Transl Med 2;14(1):197.

8. Tokito A, Jougasaki M (2016) Matrix Metalloproteinases in Non-Neoplastic Disorders. Int J Mol Sci 21;17(7). 
9. Kang YM, Hong SH, Yang JH, Oh JC, Park JO, Lee BH, Lee SY, Kim HS, Lee HM, Moon SH (2016) Pamidronate Down-regulates Tumor Necrosis Factor-alpha Induced Matrix Metalloproteinases Expression in Human Intervertebral Disc Cells. J Bone Metab 23(3):165-73.

10. Consolo M, Amoroso A, Spandidos DA, Mazzarino MC (2009) Matrix metalloproteinases and their inhibitors as markers of inflammation and fibrosis in chronic liver disease (Review). Int J Mol Med. 24(2):143-52.

11. Yamamoto K, Murphy G, Troeberg L (2015) Extracellular regulation of metalloproteinases. Matrix Biol. 44-46:255-63.

12. Gibson DJ, Schultz GS.(2013) Molecular Wound Assessments: Matrix Metalloproteinases. Adv Wound Care (New Rochelle). 2(1):18-23.

13. Utz ER, Elster EA, Tadaki DK, Gage F, Perdue PW, Forsberg JA, et al.: Metalloproteinase expression is associated with traumatic wound failure. J Surg Res 2010; 159: 633-638

14. Lloris-Carsí JM, García-Cerdá D, Prieto-Moure B, Barrios C, Martín-Ballester AB, Cejalvo-Lapeña D. (2016) Behaviour of the Biological Adhesives TachoSil ${ }^{\circledR}$, GelitaSpon ${ }^{\circledR}$, and a New Elastic Cyanoacrylate (Adhflex ${ }^{\circledR}$ ) in Experimental Renal Trauma and Wound Healing. Eur Surg Res.56(3-4):164-79.

15. Lloris-Carsí JM, Ballester-Álvaro J, Barrios C, Zaragozá-Fernández C, Gómez-De la Cruz C, González-Cuartero C, Prieto-Moure B, Cejalvo-Lapeña D. (2016) Randomized clinical trial of a new cyanoacrylate flexible tissue adhesive (Adhflex) for repairing surgical wounds. Wound Repair Regen. 24(3):568-80.

16. Ahn HB, Shin DM, Roh MS, Jeung WJ, Park WC, Rho SH. A comparison of 2-octyl cyanoacrylate adhesives versus conventional suture materials for eyelid wound closure in rabbits. Korean J Ophthalmol. 2011; 25(2): 121-127.

17. Feng CC, Wang LJ, Zhou ZW, Ding Q, Fang ZJ, Xia GW, Jiang HW, Xu G, Wen H. Positive KI67 and periodic acid-schiff mandates wider range of excision in scrotal extramammary Paget's disease. Dermatol Surg. 2013; 39(3): 381-386.

18. DeYoung BR, Swanson PE, Argenyi ZB, Ritter JH, Fitsgibbon JF, Stahl DJ, Hoover W, Wick MR. CD31 immunoreactivity in mesenchymal neoplasms of the skin and subcutis: Report of 145 cases and review of putative immunohistologic markers of endothelial differentiation. J Cutan Pathol. 1995; 22(3): 215-222.

19. Goyert SM. MC12. CD68 workshop panel report. In: Kishimoto T, Kikutani H, von dem Borne AEG, Goyert SM, Mason DY, Miyasaka M, et al., editors. Leucocyte typing VI. White cell differentiation antigens. Proceedings of the 6th International Workshop and Conference; 1996 Nov 10-14; Kobe, Japan. New York, London: Garland Publishing Inc.; 1997. p. 1015-1016.

20. C. Bonnans, J. Chou, Z. Werb. Remodeling the extracellular matrix in development and disease. Nat. Rev. Mol. Cell Biol., 2014;15: 786-801

21. Dos Santos OJ, de Souza G, Sauaia EN, Medeiros G, Pinheiro RH, Pinheiro RA (2012) Use of 2-octyl-cyanoacrylate adhesive in rat liver induced lesion. Act Cir Bras. 27(9): 624-9.

22. Dávila F, Islas HG, Carbonell JM, Hernández LM, Sánchez DJ, Rivera JM (2009) Uso del 2 cianoacrilato de N-butilo en la reparación primaria de heridas penetrantes en hígado, bazo e intestino delgado: modelo experimental en perros. Rev Sanid Milit Mex. 63(4): 182-8. 
23. Amălinei C1, Căruntu ID, Giuşcă SE, Bălan RA. Matrix metalloproteinases involvement in pathologic conditions. Rom J Morphol Embryol. 2010;51(2):215-28.

24. Hemmann S1, Graf J, Roderfeld M, Roeb E.Expression of MMPs and TIMPs in liver fibrosis - a systematic review with special emphasis on anti-fibrotic strategies. J Hepatol. 2007 May; 46 (5) :955-75.

25. Li H, Nahas Z, Feng F, Elisseeff JH, Boahene K (2013) Tissue engineering for in vitro analysis of matrix metalloproteinases in the pathogenesis of keloid lesions. JAMA Facial Plast Surg. 15(6):448-56

26. Beidler SK, Douillet CD, Berndt DF, Keagy BA, Rich PB, Marston WA (2008) Multiplexed analysis of matrix metalloproteinases in leg ulcer tissue of patients with chronic venous insufficiency before and after compression therapy. Wound Repair Regen. 16(5):642-8

27. Inkinen K, Trakainen H, Wolf H, Ravanti L, Kähäri, VM, Ahonen J. Expression and activity of matrix metalloproteinase-2 and -9 in experimental granulation tissue. APMIS 2000; 108:318-328.

28. Nessler MB, Puchata J, Chrapusta A, Nessler K, Drukata J (2014) Levels of plasma matrix metalloproteinases (MMP-2 and MMP-9) in response to INTEGRA ${ }^{\circledR}$ dermal regeneration template implantation. Med Sci monit. 20:91-96.

29. Hata S, Okamura K, Hatta M, Ishikawa H, Yamazaki J (2014) Proteolytic and Non-proteolytic Activation of Keratinocyte-Derived Latent TGF-B1 Induces Fibroblast Differentiation in a Wound-Healing Model Using Rat Skin. J Pharmacol Sci.124:230-243.

30. Toriseva M, Kähäri VM (2009) Proteinases in cutaneous wound healing. Cell Mol Life Sci. 66:203-224.

31. Toriseva M, Laato M, Carpen O, Ruohonen ST, Savontaus E, Inada M, Krane SM, Kähäri VM (2012) MMP-13 Regulates Growth of Wound Granulation Tissue and Modulates Gene Expression Signatures Involved in Inflammation, Proteolysis, and Cell Viability. PLoSONE 7(8): e42596.

32. Stern R, McPherson M, Longaker MT (1990) Histologic study of artificial skin used in the treatment of full-thickness thermal injury. J Burn Care Rehab. 11(1):7-13.

33. Dejonckheere E1, Vandenbroucke RE, Libert C. Matrix metalloproteinase8 has a central role in inflammatory disorders and cancer progression. Cytokine Growth Factor Rev. 2011 Apr;22(2):73-81.

34. Danielsen PL, Holst AV, Maltesen HR, Bassi MR, Holst PJ, Heinemeier KM, Olsen J, Danielsen CC, Poulsen SS, Jorgensen LN, Agren MS (2011) Matrix metalloproteinase-8 overexpression prevents proper tissue repair. Surgery.150(5):897-906

35. Aström P, Pirilä E, Lithovius R, Heikkola H, Korpi JT, Hernández M, Sorsa T, Salo T (2014) Matrix metalloproteinase- 8 regulates transforming growth factor- $\beta 1$ levels in mouse tongue wounds and fibroblasts in vitro. Exp Cell Res. 15;328(1):217-27

36. Toriseva M, Ala-aho R, Karvinen J, Baker AH, Marjomaki VS, et al. (2007) Collagenase-3 (MMP-13) engances remodeling of three-dimensional collagen and promotes survival of human skin fibroblasts. J Invest Dermatol. 127:49-59. 